\title{
GPC: An Expert System Based on Multi-branch Structure for Grass Pest Control Information
}

\author{
Zhigang $\mathrm{Wu}^{1}$, Zehua Zhang ${ }^{2}$, Wenxin $\mathrm{Li}^{1}$, Guangjun Wang ${ }^{2}$, and Zhihong Li ${ }^{1 \text {,* }}$ \\ ${ }^{1}$ China Agricultural University, Beijing, 100193, China \\ lizh@cau.edu.cn \\ ${ }^{2}$ Institute of Plant Protection, Chinese Academy of Agricultural Sciences, China
}

\begin{abstract}
Since 1997, 13 provinces and regions in China have experienced grass pest disasters. The average annual hazard area comprised more than 3 million mu and the annual economic losses totaled more than 20 billion Yuan. Because grassland encompasses very large areas, grass pest disasters occur suddenly and frequently; thus, they are very difficult to predict and subsequently monitor. In order to provide technical support for grassland plant protection, we need to develop effective early warning systems and effective control measures. Herein, we develop and evaluate GPC (Grass Pest Control information system), a web-based expert system for identification of grass pests, which included more than 50 species of grass pests. It has been developed by China Agricultural University and Institute of Plant Protection, Chinese Academy of Agricultural Sciences. Based on user needs, GPC was developed with ASP.NET, C\# and Microsoft SQL server 2008 database. In its development we used 8 databases including a user information database, basic information database, and identification knowledge database. This tool and information database was developed both for grassland plant protection technicians and farmers.
\end{abstract}

Keywords: grass pest, expert system, pest diagnosis, grassland.

\section{Introduction}

Since 1997, 13 provinces and regions in China have experienced grass pest disasters. The average annual hazard area comprised more than 3 million mu and the annual economic losses totaled more than 20 billion Yuan. Because of the continuous occurrence of grass pest disasters, the grassland environment has been degrading. The local agricultural production has experienced serious losses due to grass pests. Because grassland encompasses very large areas, grass pest disasters occur suddenly and frequently; thus, they are very difficult to predict and subsequently monitor. Meanwhile, as climate and ecological environment change, the types and outbreak areas of grass pests are changing yearly. In order to provide technical support for

Corresponding author, Address: Department of Entomology, College of Agronomy and Biotechnology, China Agricultural University, Beijing 100193, P.R. China. 
grassland plant protection, we need to develop effective early warning systems and effective control measures. Herein, we develop and evaluate GPC (Grass Pest Control information system), a web-based expert system for identification of grass pests, which included more than 50 species of grass pests.

Liao surveyed and classified Expert systems (ES) methodologies using 11 categories: rule-based systems, knowledge-based systems, neural networks, fuzzy Expert systems, object-oriented methodology, case-based reasoning (CBR), system architecture development, intelligent agent (IA) systems, modeling, ontology, and database methodology together with their applications for different research and problem domains [1]. Expert systems have been applied in agriculture from 1980s [212]. Most of them are developed for crop production and pest management, animal husbandry, and aquaculture [13-25]. Others also began to integrate mobile communication systems, GIS technology, etc [26-28]. Some scholars also control by expert attempted to apply Expert systems to grassland resources, plantation management, and disease control [29-33].

This paper discusses the development and evaluation of a web-based expert system for identification of grass pests, named as GPC (Grass Pest Control information system). The system included more than 50 species of grass pests. It has been developed by China Agricultural University and Institute of Plant Protection, and Chinese Academy of Agricultural Sciences.

\section{Users' Needs and Knowledge Acquisition}

\section{$2.1 \quad$ Users' Needs}

Although it is widely accepted among scientists that efficient identification work is vital to formulate viable decisions about pest control measures. It is essential, however to convince technicians and farmers that the correct identification of pests is the first step in implementing control measures. Thus, one must investigate and evaluate technicians' and farmers' attitudes and perceptions relative to any expert system. Essentially, understanding their perceptions and willingness to use the tool is crucial to enhance grassland plant protection.

The system proposed can be accessed anonymously. System users are divided into regional administrators, super administrators and system administrators. They can use and mange the system with different authorities. Regional administrators need to input and maintain local monitoring information of grass pests, and they could answer questions of farmers. Super administrators could input and maintain basic information of grass pests, notice, users' question, law information and user account. Only system administrator have authority of adjust the system parameters and data dictionary.

\subsection{Knowledge Acquisition and Information Collection}

Knowledge acquisition (KA) is the process of transferring knowledge from the sources to the engineers. The translation of the knowledge possessed by the expert into a knowledge base is the bottleneck in the process of knowledge acquisition [33-34]. To 
acquire the required knowledge, we followed the KA procedure discussed in Morpurgo and Wada [35-36]. We acquired textual information (e.g. species' morphological characteristics, biology, geographic distribution, etc.) from literature reference such as extension booklets, primary and secondary literature, , etc. We obtained symptom descriptions and the identification rules from some entomologists by Expert interviews. We discussed in depth to clarify questions and process identification. Through this method, we provided a trustworthy procedure for knowledge acquisition, which helped us build a multi-branch structural key for grass pest remote identification. We also collected a large number of pictures by photographing.

\section{System Design and Development}

\subsection{Software and Database}

GPC was designed to run on the internet. Its development was based on the use of internet techniques and SQL programming languages. It was developed with ASP.NET and C\#. The server database played a very important role in developing GPC. It was used to sort all the information and knowledge which was needed to actualize every function of the expert system. In GPC, there are 8 databases including a user information database, basic information database, and identification knowledge database. They were all designed using MS SQL Server 2008 Database.

\subsection{Inference Process}

Most of traditional expert systems for assistant diagnosis of green plant pests are based on dichotomous structure, which is rule-based. In order to be more flexible, GPC adapted multi-branch structure. In this structure, knowledge is organized in a decision tree, with nodes at different levels. It is another form of hierarchical structure has more advantages for accurate and rapid diagnosis (Fig. 1).
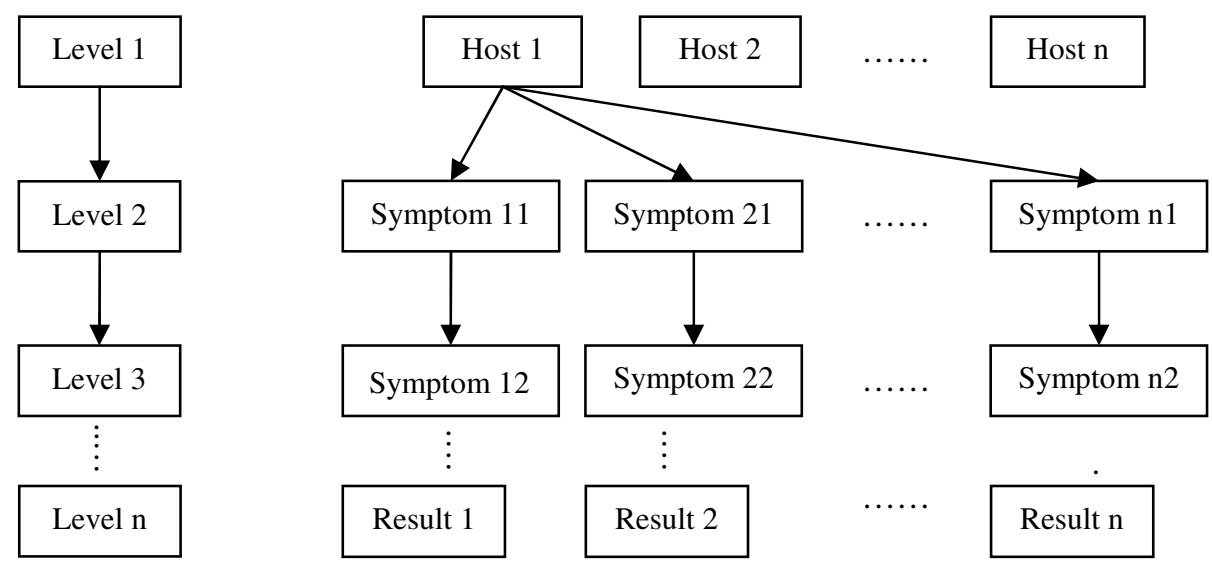

Fig. 1. The Inference diagram of multi-branch structure of GPC 


\subsection{Users Interface}

To best meet the different users' need, the design must be user-friendly. With the system, users could browse, access, and query any grass pest information easily. Meanwhile, they also can identify a grass pest by the remote pest diagnosis. Regional and super administrators can publish monitoring data and obtain statistics as needed. User interface is the direct media between users and computers, we should consider all users' knowledge level and ensure the interface complete, compact, and easy (Fig.2).

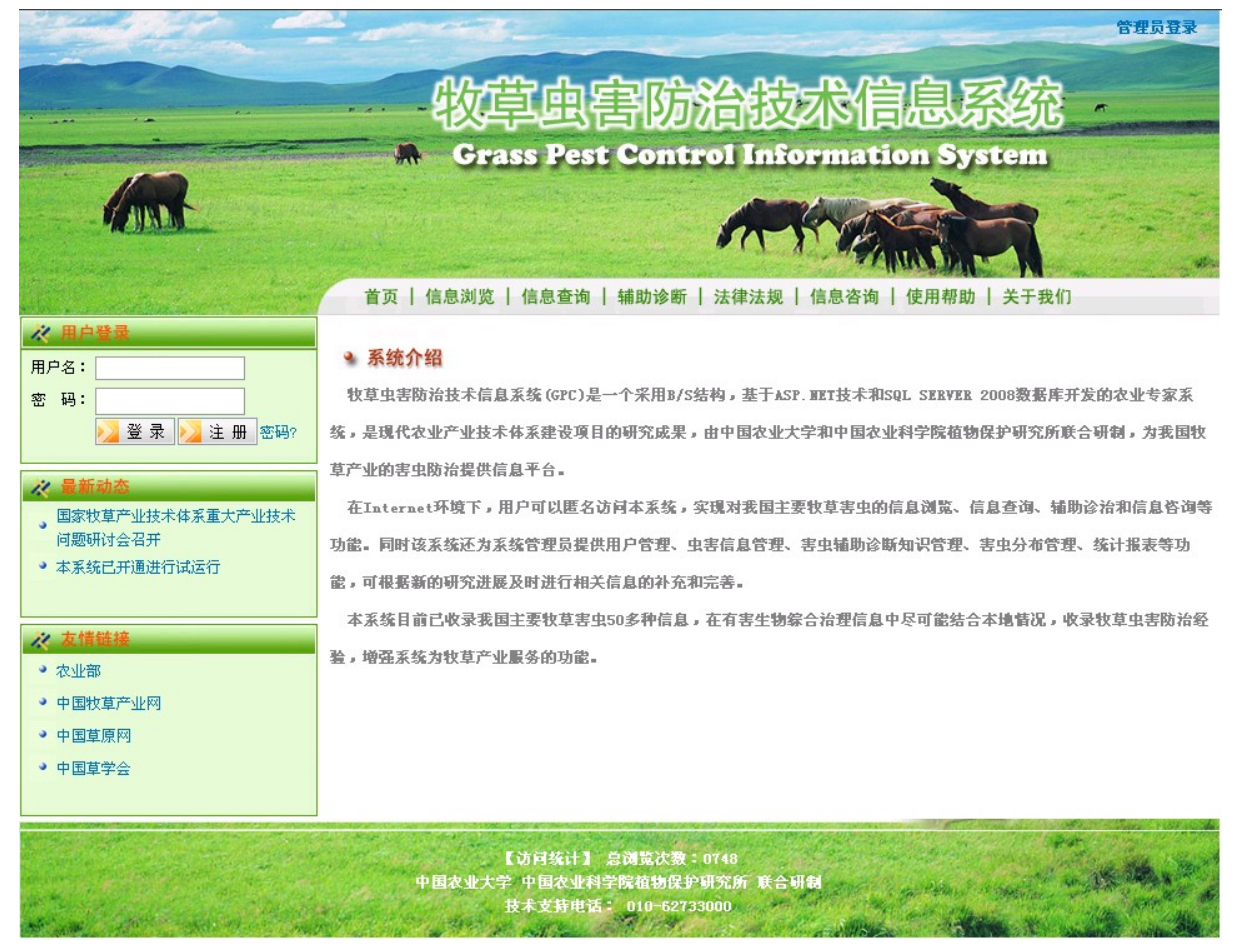

Fig. 2. Index page of GPC

\section{Discussion}

Because grass pest species are numerous and widely distributed, their prevention and control are very difficult. In order to reduce pest damage, the government needs to increase investment in the control of grass pests and improve levels and conditions of pest monitoring and forecasting; such efforts would reduce large agricultural losses. GPC can be used to remotely diagnose grass pests and provide monitoring information for farmers and technicians. All of these benefits would be enhanced if we strengthen and publicize the system, thereby permittin more people to use the system. 
The system was evaluated in two steps: verification and validation [37]. We determined the system code error and perfected it with the white-box testing method. The key which is used for pest diagnosis was also further improved by pest experts. In the second step, we had students and teachers test the system with black-box testing method. All the students selected were majors in plant protection, but without experience in grass pest identification. Although, students using the expert system were able to identify most of cases correctly, some pests with similar taxonomic characters were not easy to be identified. Presumably, it would be easier for the more experienced students or technicians.

Acknowledgements. The authors thank Prof. Stauffer at Pennsylvania State University for his valuable suggestions and modifying the draft. We are also grateful to other members of Plant Quarantine and Invasion Biology Laboratory of China Agricultural University (CAUPQL). This study received financial support from the earmarked fund for China Agriculture Research System (201003079), Special Fund for Agro-scientific Research in the Public Interest (CARS-35), Innovation Fund for Graduate Student of China Agricultural University (KYCX2010017).

\section{References}

1. Liao, S.H.: Expert system methodologies and applications-a decade reviews from 1995 to 2004. Expert Systems with Applications 28, 93-103 (2005)

2. Coulson, R.N., Saunders, M.C.: Computer-assisted decision-making as applied to entomology. Annual Review of Entomology 32, 415-437 (1987)

3. Jones, P.: Agricultural applications of expert systems concepts. Agricultural Systems 31, 3-18 (1989)

4. Travis, J.W., Latin, R.X.: Development, implementation, and adoption of expert systems in plant pathology. Annual Review Phytopathology 29, 343-360 (1991)

5. Edwards Jones, G.: Knowledge-based systems for pest management: an application-based review. Pesticide Sciences 36, 143-153 (1992)

6. Edwards Jones, G.: Knowledge-based systems for crop protection: theory and practice. Crop Protection 12, 565-575 (1993)

7. Ramon, M.C.U., Roland, F.: An expert advisory system for wheat disease management. Plant Disease 78, 209-215 (1994)

8. Yialouris, C.P., Sideridis, A.B.: An expert system for tomato diseases. Computers and Electronics in Agriculture 14, 61-76 (1996)

9. Kramers, M.A., Conijn, C.G.M., Bastiaansen, C.: EXSYS, an Expert System for Diagnosing Flower bulb Diseases, Pests and Non-parasitic Disorders. Agricultural System 58, 57-85 (1998)

10. Ellison, P., Ash, G., McDonald, C.: An expert system for the management of botrytris cinerea in Australian vineyards. Development, Agricultural Systems 56, 185-207 (1998)

11. Clarke, N.D., Leslie Shipp, J., Papadopoulos, A.P.: Development of the Harrow Greenhouse Manager: a decision-support system for greenhouse cucumber and tomato. Computers and Electronics in Agriculture 24, 195-204 (1999)

12. El-Azhary, E., Hassan, H.A., Rafea, A.: Pest control expert system for tomato (PCEST). Knowledge and Information Systems 2, 242-257 (2000) 
13. Mahaman, B.D., Harizanis, P., Filis, I.: A diagnostic expert system for honeybee pests. Computers and Electronics in Agriculture 36, 17-31 (2002)

14. Mahaman, B.D., Passam, H.C., Sideridis, A.B.: DIARES-IPM: a diagnostic advisory rulebased expert system for integrated pest management in Solanaceous crop systems. Agricultural Systems 76, 1119-1135 (2003)

15. Gonzalez Andújar, J.L., Fernandez-Quintanilla, C., Izquierdo, J.: SIMCE: An expert system for seedling weed identification in cereals. Computers and Electronics in Agriculture 54, 115-123 (2006)

16. Prasad, R., Kumar Rajeev, R., Sinha, A.K.: AMRAPALIKA: An expert system for the diagnosis of pests, diseases, and disorders in Indian mango. Knowledge-Based Systems 19, 9-21 (2006)

17. Mansingh, G., Reichgelt, H., Osei Bryson, K.: CPEST: An expert system for the management of pests and diseases in the Jamaican coffee industry. Expert Systems with Applications 32, 184-192 (2007)

18. López-Morales, V., López-Ortega, O., Ramos-Fernańdez, J.: JAPIEST: An integral intelligent system for the diagnosis and control of tomatoes diseases and pests in hydroponic greenhouses. Expert Systems with Applications 35, 1506-1512 (2008)

19. Li, D., Fu, Z., Duan, Y.: Fish-Expert: a web-based expert system for fish disease diagnosis. Expert Systems with Applications 23, 311-320 (2002)

20. Fu, Z., Xu, F., Zhou, Y.: Pig-vet: a web-based expert system for pig disease diagnosis. Expert Systems with Applications 29, 93-103 (2005)

21. Xiao, J., Wang, H., Gao, L.: Design and Implementation of Expert System for Cow Disease Diagnose Based on. NET Framework. Application Research of Computers 12, 247-248 (2006) (in Chinese)

22. Liu, S., Xu, L., Shen, Y.: Design and implementation of expert system for prawn disease diagnose and prevention based on. NET platform. Computer Engineering and Design 13, 3444-3447 (2008) (in Chinese)

23. Li, Z., Zhang, B., Shen, Z.: The development of Quarantine Pests Information and Identification System in China. Plant Quarantine 17, 273-276 (2003) (in Chinese)

24. Shao, G., Li, Z., Wang, W.: Study on vegetable pests remote diagnosis expert system (VPRDES). Plant Protection 1, 51-54 (2006) (in Chinese)

25. Han, H., Rajotte, E.G., Li, Z.: Qpais: A Web-Based Expert System for Assistedidentification of Quarantine Stored Insect Pests. In: Computer and Computing Technologies in Agriculture II, vol. I, pp. 701-714. Springer, Boston (2009)

26. Yu, S., Zhu, W.: Research on Mobile Expert System of Tomato Pest Diagnose Based on Microsoft. Net and Web Service. Journal of Agricultural Mechanization Research 1, 206-210 (2006) (in Chinese)

27. Wang, A., Miao, T., Cao, J.: Study of Web - Based Expert System for Control of Diseases and Insects in Forest. Computer Technology and Development 4, 228-231, 235 (2008)

28. Xiao, L., Wang, Z., Peng, X.: Remote Diagnosis and Control Expert System for Citrus Agricultural Diseases and Insect Pests Based on BP Neural Network and WebGIS. In: Second International Conference on Intelligent Computation Technology and Automation, pp. 88-93 (2009)

29. Liu, S.: Approach of Grass Resources Classification Expert System (GES). Journal of Wuhan Technical University of Surveying and Mapping 19(1), 45-51 (1994)

30. Shi, W., Nie, S., Ma, Y.: National Database and Information Service System for Forage Germplasm Resources. Grassland of China 2, 20-22, 32 (1996)

31. Wang, Y., Yang, Y.: Analysis and design of GIS based expert system for pasture growing management. Pratacultural Science 20(1), 61-64 (2004) 
32. Ma, Z., Ren, Q.: Preliminary study on the system management model of forage grass diseases in Ningxia. Journal of Ningxia Agricultural College 15(3), 23-28 (1994)

33. Edward Jones, G.: Knowledge-based systems for pest management: an application-based review. Pestic 36, 143-153 (1992)

34. Plant, R.E., Stone, N.D.: Knowledge-based Systems in Agriculture. McGraw-Hill, New York (1991)

35. Morpurgo, R., Mussi, S.: I-DSS: an Intelligent Diagnostic Support System. Expert Systems 18, 43-58 (2001)

36. Wada, T., Motoda, H., Washio, T.: Knowledge Acquisition from Both Human Expert and Data. In: Cheung, D., Williams, G.J., Li, Q. (eds.) PAKDD 2001. LNCS (LNAI), vol. 2035, pp. 550-561. Springer, Heidelberg (2001)

37. Harrison, S.R.: Validation of agricultural expert systems. Agric. Syst. 35, 265-285 (1991) 